\title{
Endoscopic thoracic microdiscectomy
}

\author{
Rod J. Oskouian, M.D., ANd J. Patrick Johnson, M.D. \\ Department of Neurological Surgery, University of Virginia Health Systems, Charlottesville, Virginia; \\ and Institute of Spinal Disorders, Cedars-Sinai Medical Center, Los Angeles, California
}

\begin{abstract}
Object. The purpose of this investigation was to evaluate surgical and neurological outcomes in thoracic disc surgery in a prospective fashion.

Methods. Quantifiable outcome data such as operating time, blood loss, duration of chest tube drainage, narcotic drug use, length of hospital stay (LOS), and long-term follow up of neurological function and pain-related symptoms were collected prospectively.

In patients with myelopathy there was an improvement of two Frankel grades in the thoracoscopic discectomy group and one Frankel grade in the patients treated with thoracotomy; however, patients in the thoracotomy group were significantly worse preoperatively. None of the patients experienced worsened pain, and pain related to radiculopathy was improved by $75 \%$ in the thoracoscopic group.

Conclusions. Thoracoscopic discectomy yields acceptable surgical results and has several distinct advantages, with reduced postoperative pain, morbidity, and LOS.
\end{abstract}

\section{KEY WORDS - disc herniation - endoscopy - thoracic spine • thoracoscopy • thoracotomy}

Treatment of thoracic disc herniations is problematic for the spine surgeon because of the low incidence of this entity and delays in diagnosis that are often due to a lack of classic clinical characteristics. ${ }^{2-5,10,32,33,38,52,53}$ Previous literature on thoracic disc surgery was often collected in a retrospective fashion, spanning many years, and data on patients were often pooled, making it difficult to interpret the patient's initial clinical presentation and their neurological outcomes. $5,7,8,12,14,18,27,31,32,42,44,48,50,55$ As a result, there is a lack of quantifiable surgical data as well as information on overall neurological outcome after surgical treatment for these difficult-to-reach lesions. The purpose of this investigation was to establish criteria for outcome measurement in thoracic disc surgery. We report our results based on quantifiable operative data as well as findings of neurological outcome obtained in a prospective manner at one institution.

\section{CLINICAL MATERIAL AND METHODS}

\section{Patient Population}

Information about the clinical presentation, patient selection process, surgical techniques, outcomes, and complications in patients with symptomatic thoracic disc lesions was collected in a prospective nonrandomized fashion. All patients underwent thoracoscopic discectomy procedures performed by the senior author (J.P.J.).

Abbreviations used in this paper: LOS = length of hospital stay; $\mathrm{MR}=$ magnetic resonance; OPLL = ossification of the posterior longitudinal ligament; VB = vertebral body.
Patients were treated at the University of California at Los Angeles Medical Center and affiliated hospitals between March 1995 and February 2001 for thoracic disc lesions that included soft and calcified herniations, OPLL, and discitis.

There were 47 patients treated with thoracoscopic discectomy (21 men and 26 women) whose mean age was $53.5 \pm 6.1$ years (mean \pm standard deviation, range 27-77 years). The number of thoracic levels affected and the location and type of lesion are noted in Table 1 . The presenting clinical symptoms included myelopathy (26 patients) and radicular pain (21 patients), and the mean symptom duration in months was 8.3 (range 2-34) and 13.7 (range 2-60), respectively. All patients in our study experienced either neurological symptoms from compression of the spinal cord or radicular pain in the thoracic spine that was refractory to medical management.

\section{Selection for Thoracoscopic Discectomy or Open Thoracotomy}

The presenting symptoms or type of lesion (soft or calcified disc lesions) were not factors in the selection for thoracotomy or thoracoscopy. Patient selection was based on the number of spinal levels involved, and the presence of OPLL. All 47 patients with one- or two-level thoracic disc herniations underwent a thoracoscopic discectomy; all patients in the thoracoscopic discectomy group underwent a one- or two-level procedure.

\section{Techniques for Thoracoscopic Spine Surgery}

A detailed description of thoracoscopic spine surgery is beyond the scope of the paper and is discussed else- 
TABLE 1

Number of thoracic levels affected and type of lesion in patients with disc disorders treated with thoracoscopic discectomy

\begin{tabular}{lc}
\hline \multicolumn{1}{c}{ Characteristic } & No. of Ops \\
\hline level of lesion & 0 \\
T3-4 & 0 \\
T4-5 & 14 \\
T5-6 & 23 \\
T6-7 & 2 \\
T7-8 & 6 \\
T8-9 & 6 \\
T9-10 & 0 \\
T10-11 & 6 \\
T11-12 & \\
no. of op levels & 40 \\
one & 7 \\
two & 0 \\
three & 0 \\
four & 0 \\
five & 1.3 \\
mean & \\
type of lesion & \\
soft disc herniation & \\
single-level & 28 \\
multilevel & 0 \\
calcified disc herniation (or OPLL) & 16 \\
discitis &
\end{tabular}

where: ${ }^{15-17,26,42-46}$ we discuss only the most salient portions of the surgical procedure. The patient is placed in a lateral decubitus position; the ventilated lung is in a dependent position on the operating table that provides maximum exposure of the ipsilateral thoracic cavity (Fig. 1). Standard anesthetic monitoring protocols and operating room setup for thoracic endoscopic procedures and thoracotomy are used. The patient is also prepared for a thoracotomy in the event that conversion to this procedure is needed. Thoracotomy and thoracoscopic spinal procedures require induction of general anesthesia and an anesthesia team capable of performing double-lumen endotracheal tube placement with fiberoptic endoscopic guidance. The dou- ble-lumen endotracheal tube allows collapse of the ipsilateral lung so that the spinal procedure can be performed within the empty chest cavity while the contralateral lung receives mechanical ventilation.

Following precise localization of the disc space, the procedure begins with resection of the parietal pleura over the distal $2 \mathrm{~cm}$ of the rib head and adjacent disc space by using endoscopic scissors attached to a high-frequency electrocautery device. The proximal portion of the rib and the disc space are linear and help to orient the surgeon during the entire procedure (Fig. 2A and B). The proximal 2 $\mathrm{cm}$ of the rib is removed using a high-speed drill to expose the lateral surface of the pedicle, neural foramen, and underlying disc (Fig. 2B). The neural foramen contains epidural fat and is relatively small, with the segmental nerve and vessels coursing under the rib. The adjacent segmental vessels are usually not divided because they are located in the midportion of the VB, but they can be mobilized and divided if necessary. The dura mater of the lateral spinal cord is then exposed by removing the pedicle with the high-speed drill, which also orients the surgeon during the remainder of the procedure (Fig. 2C).

The drilling of the VBs adjacent to the disc space is a crucial step in the procedure for achieving adequate bone removal to decompress the spinal canal, and there is the potential for injuring the exiting nerve root or spinal cord during these steps. The decompression requires drilling across the posterior aspect of the VBs adjacent to the disc space and endplates that essentially undermines the floor of the spinal canal and creates a tunnel. The cortical bone on the ventral aspect of the spinal canal should remain intact until the drilling is completed, because it protects the spinal cord. Beginning at the site where the pedicle was initially removed, the floor of the spinal canal is then removed with either small Kerrison rongeurs or sharp curettage (Fig. 3A). This often requires pulling soft disc material or cracking calcified disc into the defect created by the bone decompression. This procedure completely decompresses the ventral aspect of the spinal canal from a ventrolateral endoscopic exposure (Fig. 3B).

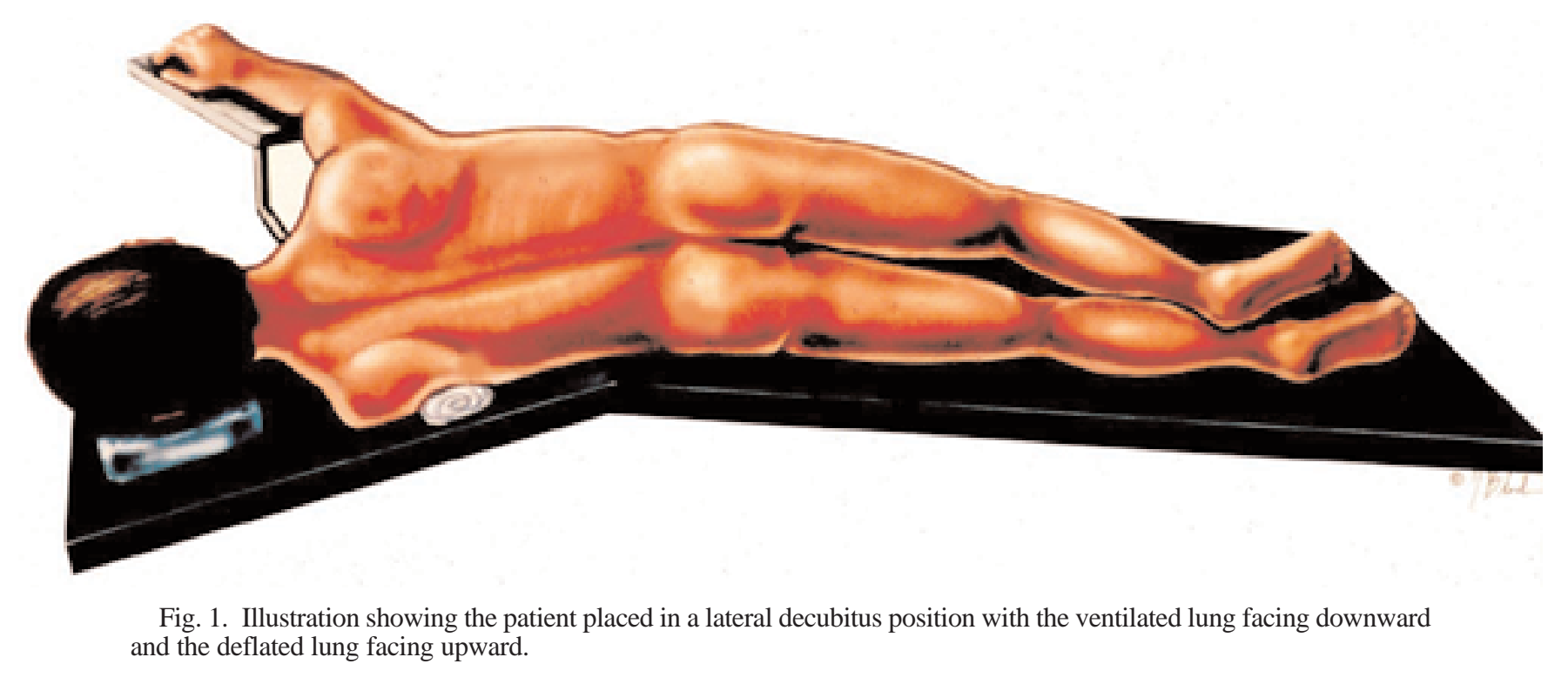




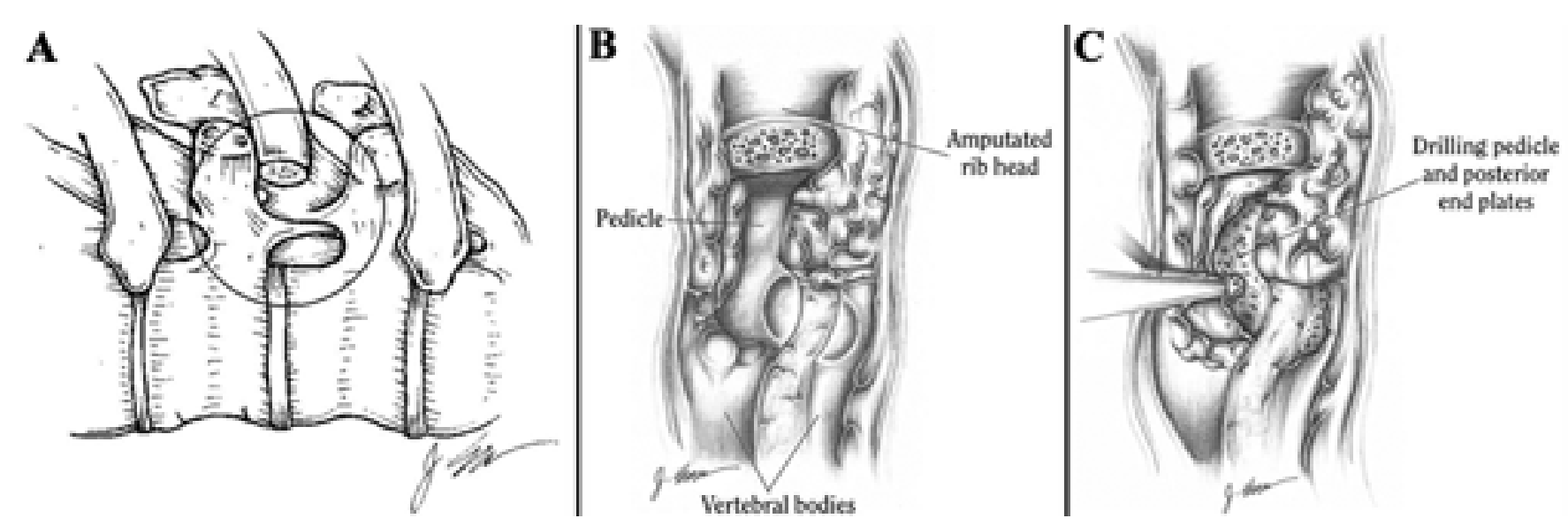

Fig. 2. An artist's illustrations showing steps in the procedure. A: A rib head and adjacent intervertebral disc space with pleura resected. B: The rib head is removed, demonstrating the underlying pedicle and disc. The thoracic levels (T1-10) and the head of the rib articulate with the same vertebra and the intervertebral disc space superior to the head of the rib. C: Beneath the spinal canal the pedicle and endplates are shown during drilling.

\section{Clinical Evaluation, Follow-Up Examination, and Statistical Methods}

Data on the operating time, blood loss, and duration of chest tube drainage were collected for each patient. All patients underwent postoperative neuroimaging to ensure that the decompression was successful. Follow-up clinical and neurological evaluations were conducted at 1, 3, 6, and 12 months postoperatively. The Oswestry Pain Scale ${ }^{20}$ questionnaire was administered to the patients with radicular pain by a third-person interviewer, and a Frankel grade $^{22}$ was assigned to patients with myelopathy to assess their neurological function.

\section{RESULTS}

The surgical and hospital data were compiled and are presented in Table 2.

\section{Outcomes in Patients With Radiculopathy}

Based on a comparison of pre- and postoperative Os- westry Pain Scale scores, patients with radiculopathy experienced a $75 \%$ improvement in terms of pain status. The mean preoperative pain score was 60 (range 40-80) and the mean postoperative score was 14 (range 0-40). All patients experienced some improvement in radiculopathy symptoms, and three patients experienced only limited improvement; however, these three patients were satisfied with the result and would undergo the procedure again. No patient experienced worsened status postoperatively.

\section{Neurological Outcomes in Patients With Myelopathy Treated With Thoracoscopic Discectomy}

The neurological outcomes for these patients were mostly improved, as reflected by postoperative Frankel grades (Table 3). Myelopathy improved in 18 (38\%) of 47 patients as indicated by a mean improvement of two Frankel grades. Myelopathy was unchanged in 27 patients $(58 \%)$, including only one whose disease remained categorized as Frankel Grade C after surgery, who had a 4year history of chronic myelopathy.
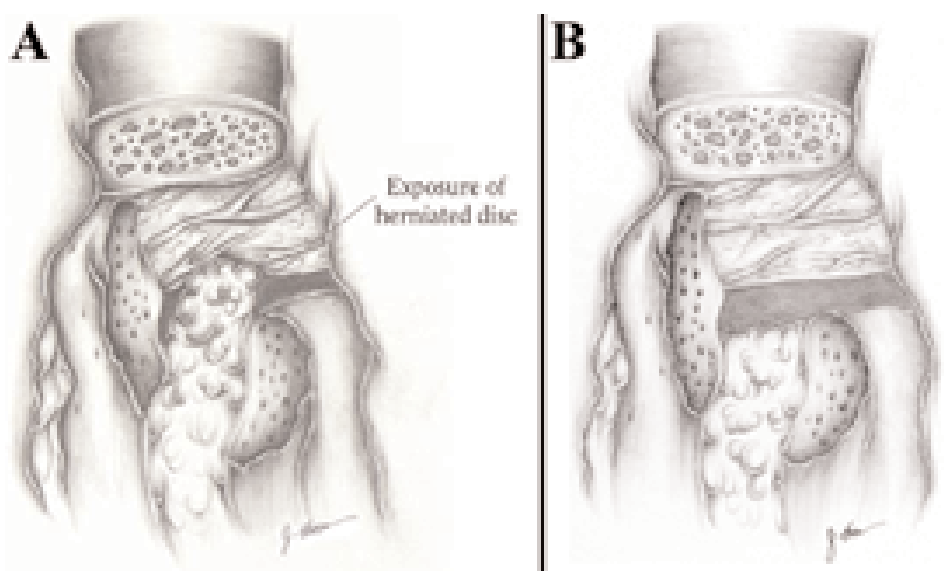

Fig. 3. An artist's illustrations showing later stages of the procedure. A: Illustration showing exposure of the intervertebral disc space site after completion of drilling and exposure of the herniated disc. B: Illustration showing a completed discectomy and decompressed spinal dura. 
TABLE 2

Operative and postoperative data obtained in 47 patients with thoracic disc herniation treated with thoracoscopic discectomy

\begin{tabular}{lc}
\hline \multicolumn{1}{c}{ Factor } & Value (range) \\
\hline op time in mins & $216(102-384)$ \\
blood loss in ml & $227(100-600)$ \\
chest tube drainage in days & $1.4(0-18)$ \\
narcotic usage in mg/day for 3 days & $6.4(4-11)^{*}$ \\
LOS in days & $3.1(1-21)$ \\
\hline
\end{tabular}

* Estimated as milligrams equivalent of morphine sulfate.

As a result, myelopathy was unchanged or improved in all but one patient (98\%) in the thoracoscopic discectomy group, whereas one patient (2\%) worsened from a Frankel Grade $\mathrm{C}$ to $\mathrm{B}$. This patient had suffered longstanding paraparesis for 30 years after undergoing a laminectomy for a large calcified thoracic disc herniation; he had been paraplegic for 1 year following laminectomy. He experienced worsening paraparesis and spastic gait and underwent thoracoscopic discectomy that was noted for removal of an intradural calcified disc that resulted in a cerebrospinal fluid leak. The leak was resolved successfully by using a muscle graft, fibrin glue, lumbar subarachnoid drainage, and by maintaining the chest tube without suction postoperatively.

\section{Complications Related to Surgery}

Minor and major complications occurred in $24 \%$ of patients who underwent thoracoscopic discectomy (Table 4). Most of these complications were transient and not life threatening. Intercostal neuralgia was the most frequent transient complication in both groups, although this had resolved in nearly all patients treated with thoracoscopic discectomy at 3 months postsurgery. One patient who continued to experience intercostal neuralgia up until 6 months postsurgery subsequently attained partial improvement after undergoing intercostal nerve blocks and a radiofrequency rhizotomy. This patient was treated early in the series, when we were using hard plastic ports; no cases of permanent neuralgia have occurred since we began to use the soft, flexible ports. All cases of pneumonia resolved after antibiotic therapy and pulmonary toilet.

Recurrent disc herniation occurred in an obese young woman who underwent thoracoscopic discectomy for pri-

TABLE 3

Preoperative and postoperative Frankel grades obtained in patients who underwent thoracoscopic discectomy

\begin{tabular}{cllllr}
\hline \hline & \multicolumn{5}{c}{ Frankel Grade (postop) } \\
\cline { 2 - 6 } Frankel Grade (preop) & A & B & C & D & E \\
\hline thoracoscopy group & & & & & \\
A & & & & & \\
B & & & & 4 & \\
C & & $1 *$ & 3 & 4 & 6 \\
D & & & 14 & 4 \\
E & & & & 10 \\
\hline
\end{tabular}

* Patient was worsened postoperatively. marily chest wall pain and a mild myelopathy. Thoracoscopic reexploration was converted to an open thoracotomy procedure, and the disc was removed uneventfully, resulting in improvement in her pain symptoms. Chylothorax developed in one patient in the thoracoscopytreated group, although no leak had been noted at surgery. There was a persistent high output of chyle from the chest tube. The patient was treated by withholding oral feedings and received elemental total parenteral nutrition therapy for 2 weeks, which resolved the leak.

\section{DISCUSSION}

Almost a century ago the concept of using an endoscope to view the thoracic cavity was proposed for lysis of tubercular pleural adhesions as an alternative to open thoracotomy. ${ }^{25}$ These maximally invasive thoracotomy and posterior-lateral paraspinal procedures provided the impetus for development of minimally invasive thoracoscopic techniques for thoracic spinal lesions. ${ }^{6,15-17,26,33,42-46}$ The trend of minimally invasive procedures for thoracic spinal surgery has similarly evolved, with use of thoracoscopy for ventral lesions to gain adequate exposure of these anatomically challenging entities that require specialized surgical techniques. . $^{15-17,23,26,29,33,36,42-46,49}$

\section{Natural History and Pathophysiological Disorders of Thoracic Discs}

Thoracic disc herniations are rare in comparison with those in either cervical or lumbar discs. The incidence of thoracic disc herniation is estimated to be between 0.25 and $1 \%$ of all such lesions, and population studies indicate that the overall incidence of thoracic disc herniations is approximately 1 per million patient-years. ${ }^{1,10,50}$ Thoracic disc herniations typically present with a variety of nonspecific symptoms, frequently leading to a wrong or delayed diagnosis. . $4,33,53^{2}$

The vast majority of thoracic disc herniations are found

TABLE 4

Surgery-related complications after thoracoscopic discectomy in 46 patients with thoracic herniated discs*

\begin{tabular}{lc}
\hline \multicolumn{1}{c}{ Complication } & No. $(\%)$ \\
\hline atelectasis & $3(6)$ \\
pleural effusion & $2(4)$ \\
pneumonia & $2(4)$ \\
intercostal neuralgia & \\
transient $(<3$ mos) & $5(11)$ \\
permanent $(>3$ mos) & $1(2)$ \\
recurrent disc herniation & $1(2)$ \\
chylothorax & $1(2)$ \\
hemothorax & $0(0)$ \\
wrong level & $1(2)$ \\
infection & $0(0)$ \\
inadequate discectomy & $2(4)$ \\
subcutaneous emphysema & $0(0)$ \\
neurological deterioration & $1(2)$ \\
additional neurological deficit & $1(2)$ \\
death & 0 \\
total & $11(24)$ \\
\hline
\end{tabular}

* More than one complication per patient. 
in patients between the third and fifth decades of life below the level of T-7. The eighth, ninth, and 10th ribs are fused to the sternum with cartilage, whereas the 11th and 12th ribs are not attached to the sternum at all, which is thought to contribute to the greater degree of flexibility in this region. Given the biomechanical stresses on the thoracic spine, the greater degree of flexion allowable at each vertebral level corresponds to a higher incidence of nucleus pulposus herniations.${ }^{54}$ Interestingly, the most common level of lesion in our study in both groups was at the T6-7 disc space (Table 1).

Stillerman, et al., ${ }^{50}$ classified the symptoms of thoracic discs into localized thoracolumbar pain, radicular pain, and myelopathy. Surprisingly, almost $25 \%$ of their patients did not present with symptomatic pain. The most common presenting symptom was pain, which approximately $75 \%$ of their patients reported; myelopathy was actually the second most common presenting symptom. Although pain was also the most common presenting symptom in our group of patients, only four of the participants in our study did not have myelopathy.

\section{Thoracic Disc Surgery}

The surgical management of thoracic disc herniations has undergone an evolution in recent years in both diagnosis and treatment. ${ }^{15-18,21,23,26,28,29,31,37,42-46,50-52}$ Nonetheless, the spine surgeon is still confronted with the unique anatomy of central disc herniations in the thoracic spine and must choose the optimal approach for decompression. Myelopathy is a clear indication for surgery, but the role of surgery for radicular pain is controversial. It remains unlikely that a true randomized prospective study in which thoracotomy is compared with thoracoscopic discectomy will occur, because patients seeking minimally invasive procedures from surgeons skilled in these techniques would not agree to a thoracotomy as a primary procedure. Thoracoscopic discectomy is a minimally invasive procedure that is an alternative to traditional open thoracotomy or posterolateral transpedicular and costotransversectomy approaches. Thoracoscopic operations have been well established as the procedures of choice compared with thoracotomy because of reduced rates of morbidity. ${ }^{28,43-45}$

\section{Neurological and Surgical Outcome}

In neurosurgical practice, outcome data are used to measure the efficacy of a surgical procedure. In the past, outcomes were loosely defined and there were no clear surgery-related outcome parameters. In spine surgery there are probably no pathological entities in which it is more difficult to quantify outcome than in those treated with thoracic disc surgery. The difficulties related to determining outcome in thoracic disc surgery have historically been severe. First, the natural history of the disease is not so clear, therefore making it difficult to determine which patients would actually benefit from receiving surgery ${ }^{33}$ Second, the incidence of thoracic disc herniation is extremely low, with an estimated incidence of $1 \%$ of all herniated discs.

Historically, surgical outcomes for patients undergoing thoracic disc surgery were reported as the number of patients benefiting from the procedure compared with the number with postoperative complications. Moreover, in recent studies investigators have concluded that thoracoscopic discectomy is the method preferred; however, these conclusions were based on historical comparisons that were difficult to interpret. To make the matter even more complicated, there have been small series of patients who underwent treatment of thoracic discs in which the groups were subdivided based on the approach. ${ }^{37}$ Last, the surgical management of disorders in thoracic discs has become a controversial issue to a number of spine surgeons, who have proposed various surgical approaches. The optimal approach for herniated thoracic discs remains unclear, and the literature regarding the efficacy, indications, or limitations of thoracoscopic disc surgery has not been established. Today, the surgical approaches used to reach these anatomically challenging lesions are transthoracic, modified costotransversectomy or lateral extracavitary, transpedicular or transfacet, and thoracoscopic microdiscectomy. $7,8,11,12,15-18,21,23-25,29-39,45-48,51$

In previous reports thoracoscopic discectomy was compared with open thoracotomy and costotransversectomy, and all investigators concluded that thoracoscopy is advantageous based on the lower morbidity rates. ${ }^{15,34,36,43,45}$ Moreover, other authors have made comparisons with cases from the 1980s and/or pooled their retrospective studies. Although they provided interesting comparisons, these lack validity because surgical and anesthetic procedures as well as postoperative management practices were

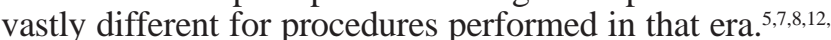
$14,18,27,31,32,43,44,48,50,55$ For example, in a thoracotomy or costotransversectomy procedure performed today for the treatment of an uncomplicated thoracic lesion, the incision would be smaller and the operating time, postoperative pain medications, and LOS would likely be cut by $50 \%$ compared with the same procedure a decade ago. Even today, LOS and operating time vary widely between surgeons and their respective institutions (Table 5).

Patients who underwent thoracoscopic discectomy had shorter operating times, less blood loss, a shorter period of dependence on chest tube drainage, less narcotic usage, and a shorter LOS. These findings were statistically significant for shorter LOS and narcotic drug usage $(\mathrm{p}<0.05)$. Pain related to radiculopathy was improved by $75 \%$, and none of our patients experienced worsened pain. In patients with myelopathy there was an improvement of two Frankel grades in the thoracoscopic group.

\section{Surgical Approaches}

Anterior approaches to the thoracic spinal column have become established as standard for appropriate treatment of disc lesions primarily anterior to the spinal cord. ${ }^{9,19,26 \text {, }}$ 40,41,48 Thoracotomy remains the standard open procedure that provides optimal ventral exposure of these anterior spinal lesions. . $^{2,5,8,11,13,19,24,33,40,41,48}$ Alternatively, the costotransversectomy and transpedicular techniques provide a posterolateral exposure that avoids opening the chest; however, direct visualization of the ventral spinal cord is not possible. ${ }^{11,21,28,30,31,33,35,39,51,52}$ With the exception of the lateral extracavitary and transpedicular approaches that follow a posterior and lateral trajectory to the disc along the rib or pedicle, respectively, the thoracotomy remains the gold standard for treatment of ventral midline lesions 
R. J. Oskouian and J. P. Johnson

TABLE 5

Literature review of surgical outcome after thoracic disc surgery*

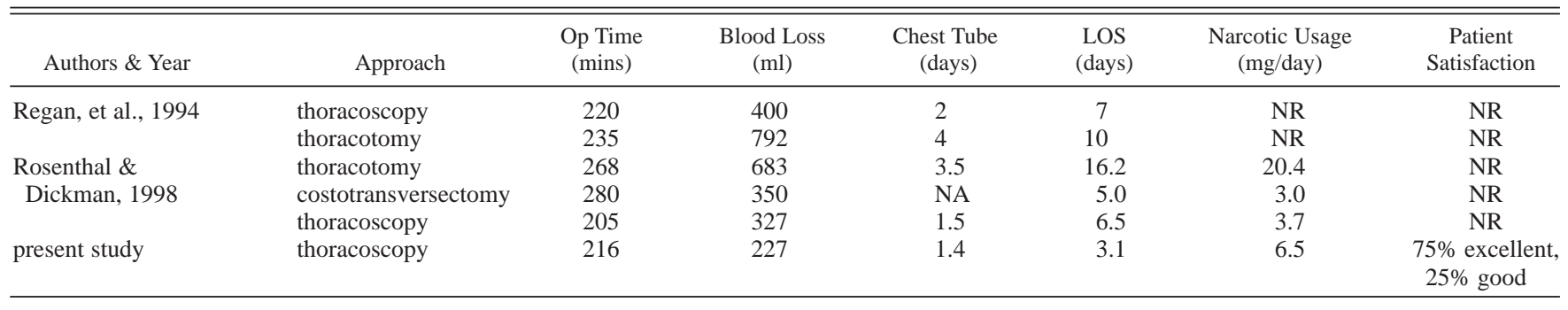

$* \mathrm{NA}=$ not applicable; $\mathrm{NR}=$ not reported.

compressing the spinal cord. ${ }^{39,40}$ Furthermore, the lateral extracavitary and transpedicular approaches do not provide direct visualization of lesions directly ventral to the spinal cord, which cannot always be removed safely without possible injury to the spinal cord. This is particularly true with midline calcified disc lesions that require an anterior transthoracic approach. ${ }^{40,41}$

We also believe that a thoracotomy may be the best procedure in patients harboring such complex multilevel thoracic lesions as OPLL, in which the operating time and risks may exceed the perceived advantages of an endoscopic procedure. These lesions typically compress a contiguous segment of the spinal cord rather than featuring focal herniated disc lesions, and would require that several additional ports be placed, thus contributing to a longer operating time than for a thoracotomy. Although a thoracoscopy for complex multilevel thoracic lesions is indeed feasible, it may not be practical if the procedure requires a significantly longer time and potentially greater risk to the patient.

The nonrandomized nature of our study weakens our data somewhat because there is an inherent selection bias in nonrandomized retrospective studies. The indications for each technique are different; therefore, it is not possible to compare one treatment with the other. The patients who were selected for thoracoscopic spine surgery were clearly different from those chosen for thoracotomy. As a result, the physiological effects observed for each group and their respective treatments could have been influenced by patient selection.

\section{Limitations of Thoracoscopic Surgery}

The primary disadvantages of thoracoscopic spinal procedures are several very important differences in the way the procedures are performed: endoscopic visualization, even with the latest three-dimensional technology, still depends on television projections in which the depth of field does not compare with direct stereoscopic vision. The three-dimensional glasses are sufficiently inconvenient that many surgeons still use two-dimensional endoscopes. Frequent cleaning of bone dust from the endoscope during the drilling procedure significantly interrupts the flow of the operation. The ports placed in the chest wall significantly restrict the surgeon's ability to manipulate the instruments, and they act as a fulcrum as opposed to the usually unlimited degrees of motion allowed within an open thoracotomy incision. The instruments are usual- ly longer and more awkward to use with fine dexterity than are open surgical instruments; it is also difficult for the surgeon to use instruments in each hand simultaneously to perform complex tasks with both hands, and most rely on an experienced assistant.

The need for acquiring difficult new visuomotor surgical skills is also a factor; a high level of new skills is required for the surgeon to perform this complex proce-

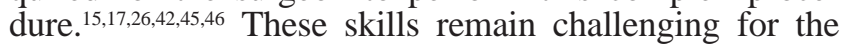
surgeon who performs them on a regular basis, and may be impractical for one who performs them infrequently. The learning curve is steep, as confirmed by surgeons who perform the procedure frequently, and formal training is recommended. It also seems appropriate to ascertain that a sufficient number of cases are treated annually to maintain necessary skills effectively.

\section{CONCLUSIONS}

The literature on prospective neurological outcome data for thoracic spine surgery is lacking and only a small series of retrospective studies have been published. It is essential to compare newer techniques such as thoracoscopy with those (such as thoracotomy) that are already established as the gold standard.

We conducted a prospective nonrandomized study in which we collected quantifiable operative and neurological outcomes data. Based on our experience, we conclude that one- and two-level thoracic lesions are ideally treated using endoscopic techniques, because the minimal incision-related pain and morbidity are markedly different from those associated with a thoracotomy. Patients undergoing thoracoscopic discectomy experienced reduced surgery-related pain, morbidity, LOS, and complications. The need for adequate training and consistent surgical experience are paramount for spine surgeons performing this technically demanding procedure. The alternative techniques (transthoracic, modified costotransversectomy or lateral extracavitary, and the transpedicular or transfacet approaches) clearly remain viable and effective for surgeons experienced in these procedures who have limited experience with thoracoscopic spine surgery.

\section{Acknowledgment}

We thank Joshua Emerson for the illustrations in this paper.

\section{Disclaimer}

We have no conflicts of interest regarding this manuscript. 


\section{References}

1. Arce CA, Dohrmann GJ: Thoracic disc herniation. Improved diagnosis with computed tomographic scanning and a review of the literature. Surg Neurol 23:356-361, 1985

2. Arseni C, Nash F: Thoracic intervertrebral disc protrusion: a clinical study. J Neurosurg 17:418-430, 1960

3. Awwad EE, Martin DS, Smith KR Jr, et al: Asymptomatic versus symptomatic herniated thoracic discs: their frequency and characteristics as detected by computed tomography after myelography. Neurosurgery 28:180-186, 1991

4. Ball PA, Benzel EC: Pathology of disc degeneration, in Menezes AH, Sonntag VKH (eds): Principles of Spinal Surgery. New York: McGraw-Hill, 1996, pp 507-516

5. Benjamin V: Diagnosis and management of thoracic disc disease. Clin Neurosurg 30:577-605, 1983

6. Benzel EC: Biomechanics of Spine Stabilization: Principles and Clinical Practice. New York: McGraw-Hill, 1995

7. Bilsky MH, Patterson RH: The transpedicular approach for thoracic disc herniations, in Benzel EC, Stillerman CB (eds): The Thoracic Spine. St. Louis: Quality Medical, 1999, pp 311-323

8. Bohlman HH, Zdeblick TA: Anterior excision of herniated thoracic discs. J Bone Joint Surg Am 70:1038-1047, 1988

9. Broc GG, Crawford NR, Sonntag VKH, et al: Biomechanical effects of transthoracic microdiscectomy. Spine 22:605-612, 1997

10. Brown CW, Deffer PA Jr, Akmakjian J, et al: The natural history of thoracic disc herniation. Spine 17 (Suppl 6):S97-S102, 1992

11. Chou SN, Seljeskog EL: Alternative surgical approaches to thoracic spine. Clin Neurosurg 20:306-321, 1973

12. Currier BL, Eismont FJ, Green BA: Transthoracic disc excision and fusion for herniated thoracic discs. Spine 19:323-328, 1994

13. Dajczman E, Gordon A, Kreisman H, et al: Long-term postthoracotomy pain. Chest 99:270-274, 1991

14. Delfini R, Lorenzo ND, Ciappetta P, et al: Surgical treatment of thoracic disc herniation: a reappraisal of Larson's lateral extracavitary approach. Surg Neurol 45:517-523, 1996

15. Dickman CA, Karahalios DG: Thoracoscopic spinal surgery. Clin Neurosurg 43:392-422, 1996

16. Dickman CA, Mican CA: Multilevel thoracic discectomies and anterior interbody fusion using a microsurgical thoracoscopic approach. Case report. J Neurosurg 84:104-109, 1996

17. Dickman CA, Rosenthal DJ, Perin NI: Thoracoscopic microsurgical discectomy, in Dickman CA, Rosenthal DJ, Perin NI (eds): Thoracoscopic Spine Surgery. New York: Thieme Medical Publishers, 1999, pp 221-244

18. el-Kalliny M, Tew JM Jr, van Loveren $\mathrm{H}$, et al: Surgical approaches to thoracic disc herniations. Acta Neurochir 111: 22-32, 1991

19. Faciszewski T, Winter RB, Lonstein JE, et al: The surgical and medical perioperative complications of anterior spinal fusion surgery in the thoracic and lumbar spine in adults. A review of 1223 procedures. Spine 20:1592-1599, 1995

20. Fairbank JC, Couper J, Davies JB,et al: The Oswestry low back pain disability questionnaire. Physiotherapy 66:271-273, 1980

21. Fessler RG, Dietze DD Jr, MacMillan M, et al: Lateral parascapular extrapleural approach to the upper thoracic spine. $\mathbf{J}$ Neurosurg 75:349-355, 1991

22. Frankel HL, Hancock DO, Hyslop G, et al: The value of postural reduction in the initial management of closed injuries of the spine with paraplegia and tetraplegia. I. Paraplegia 7: 179-192, 1969

23. Horowitz MD, Moossy JJ, Julian T, et al: Thoracic discectomy using video assisted thoracoscopy. Spine 19:1082-1086, 1994

24. Hulme A: The surgical approach to thoracic intervertebral disc protrusions. J Neurol Neurosurg Psychiatry 23:133-137, 1960

25. Jacobeus HC: Possibility of the use of the cytoscope for investigation of serous cavities. Munchen Med Wochenschr 57: 2090-2092, 1910 (Ger)

26. Johnson JP, Filler AG, McBride DQ: Endoscopic thoracic discectomy. Neurosurg Focus 9 (4):E11, 2000

27. Korovessis PG, Stamatakis MV, Baikousis A, et al: Transthoracic disc excision with interbody fusion. 12 patients with symptomatic disc herniation followed for 2-8 years. Acta Orthop Scand Suppl 275:12-16, 1997

28. Landreneau RJ, Hazelrigg SR, Mack MJ, et al: Postoperative pain-related morbidity: video-assisted thoracic surgery versus thoracotomy. Ann Thorac Surg 56:1285-1289, 1993

29. Landreneau RJ, Mack MJ, Hazelrigg SR, et al: Video-assisted thoracic surgery: basic technical concepts and intercostal approach strategies. Ann Thorac Surg 54:800-807, 1992

30. Larson SJ, Holst RA, Hemmy DC, et al: Lateral extracavitary approach to traumatic lesions of the thoracic and lumbar spine. J Neurosurg 45:628-637, 1976

31. Le Roux PD, Haglund MM, Harris AB: Thoracic disc disease: experience with the transpedicular approach in twenty consecutive patients. Neurosurgery 33:58-66, 1993

32. Lesoin F, Rousseaux M, Autricque A, et al: Thoracic disc herniations: evolution in the approach and indications. Acta Neurochir 80:30-34, 1986

33. Love JG, Schorn VG: Thoracic-disc protrusions. JAMA 191: 627-631, 1965

34. Mack MJ, Regan JJ, Bobechko WP, et al: Application of thoracoscopy for diseases of the spine. Ann Thorac Surg 56: 736-738, 1993

35. Maiman DJ, Larson SJ, Luck E, et al: Lateral extracavitary approach to the spine for thoracic disc herniation: report of 23 cases. Neurosurgery 14:178-182, 1984

36. McAfee PC, Regan JR, Zdeblick T, et al: The incidence of complications in endoscopic anterior thoracolumbar spinal reconstructive surgery. A prospective multicenter study comprising the first 100 consecutive cases. Spine 20:1624-1632, 1995

37. Mulier S, Debois V: Thoracic disc herniations: transthoracic, lateral, or posterolateral approach? A review. Surg Neurol 49: 599-608, 1998

38. Oskouian RJ Jr, Johnson JP, Regan JJ: Thoracoscopic microdiscectomy. Neurosurgery 50:103-109, 2002

39. Patterson RH Jr, Arbit E: A surgical approach through the pedicle to protruded thoracic discs. J Neurosurg 48:768-772, 1978

40. Perot PL Jr, Munro DD: Transthoracic removal of midline thoracic disc protrusions causing spinal cord compression. J Neurosurg 31:452-458, 1969

41. Ransohoff J, Spencer F, Siew F, et al: Transthoracic removal of thoracic disc. Report of three cases. J Neurosurg 31:459-461, 1969

42. Regan JJ, Mack MJ, Picetti GD III: A technical report on videoassisted thoracoscopy in thoracic spinal surgery. Spine 20: 831-837, 1995

43. Regan JJ, Mack MJ, Picetti GD III, et al: A comparison of video-assisted thoracoscopic surgery (VATS) with open thoracotomy in thoracic spinal surgery. Today's Ther Trends 11: 203-218, 1994

44. Rosenthal D, Dickman C, Lorenz R, et al: Thoracic disc herniation: early results after surgical treatment using microsurgical endoscopy. J Neurosurg 84:334A, 1996 (Abstract)

45. Rosenthal D, Dickman CA: Thoracoscopic microsurgical excision of herniated thoracic discs. J Neurosurg 89:224-235, 1998

46. Rosenthal D, Rosenthal R, de Simone A: Removal of a protruded thoracic disc using microsurgical endoscopy. A new technique. Spine 19:1087-1091, 1994 
47. Sebring LA, Maiman DJ, Larson SJ: Lateral extracavitary approach, in Benzel EC, Stillerman CB (eds): The Thoracic Spine. St. Louis: Quality Medical, 1999, pp 331-338

48. Sekhar LN, Jannetta PJ: Thoracic disc herniation: operative approaches and results. Neurosurgery 12:303-305, 1983

49. Simpson JM, Silveri CP, Simeone FA, et al: Thoracic disc herniation. Re-evaluation of the posterior approach using a modified costotransversectomy. Spine 18:1872-1877, 1993

50. Stillerman CB, Chen TC, Couldwell WT, et al: Experience in the surgical management of 82 symptomatic herniated thoracic discs and review of the literature. J Neurosurg 88:623-633, 1998

51. Stillerman CB, Chen TC, Day JD, et al: The transfacet pediclesparing approach for thoracic disc removal: cadaveric morphometric analysis and preliminary clinical experience. J Neurosurg 83:971-976, 1995

52. Stillerman CB, Weiss MH: Management of thoracic disc disease. Clin Neurosurg 38:325-352, 1992
53. Tarlov EC. Thoracic disc herniation, in Tarlov EC (ed): Neurosurgical Treatment of Disorders of the Thoracic Spine. Chicago: AANS, 1991, pp 53-59

54. White AA III, Panjabi MM: Clinical Biomechanics of Spine. Philadelphia: Lippincott Williams \& Wilkins, 1990

55. Young S, Karr G, O’Laoire SA: Spinal cord compression due to thoracic disc herniation: results of microsurgical posterolateral costotransversectomy. Br J Neurosurg 3:31-38, 1989

Manuscript received january 5, 2005

Accepted in final form February 21, 2005.

Address reprint requests to: J. Patrick Johnson, M.D., CedarsSinai Insitute for Spinal Disorders, 444 South San Vincente Boulevard, Suite 800, Los Angeles, California 90048. email: johnsonjp@ cshs.org. 